\title{
PCR detection of toxic shock syndrome toxin of Staphylococcus aureus from Tripoli, Libya
}

Correspondence

Khalifa Sifaw Ghenghesh

ghenghesh_micro@yahoo.com

Received 19 May 2005

Accepted 10 October 2005

\author{
Abdulmula El-Ghodban, ${ }^{1}$ Khalifa Sifaw Ghenghesh, ${ }^{2}$ Károly Márialigeti, ${ }^{1}$ \\ Hamida Esahli ${ }^{3}$ and Abdurrahman Tawil ${ }^{4}$ \\ ${ }^{1}$ Department of Microbiology, Faculty of Science, Etövös Loránd University, Budapest, Hungary \\ 2,3,4 Departments of Medical Microbiology ${ }^{2}$ and Pediatrics ${ }^{3}$, Faculty of Medicine, and Department \\ of Botany, Faculty of Sciences ${ }^{4}$, PO Box 80013, Al-Fateh University, Tripoli, Libya
}

\begin{abstract}
Sixty-three Staphylococcus aureus strains (40 from clinical sources and 23 from food sources) were examined for toxic shock syndrome toxin-1 (TSST-1) using PCR, phage typed using the international phage set (IPS) and tested for their susceptibility to antibiotics. Only three strains (all from clinical sources) were positive for the TSST-1 gene ( $t s t$ ). The majority of $S$. aureus strains that were typeable by IPS belonged to group II. Resistance to one or more antibiotics was detected in 47.5 and $73.9 \%$ of clinical and food strains, respectively. This is the first time that PCR detection of tst in $S$. aureus has been reported from Libya, and further studies are needed on the occurrence of toxic shock syndrome in the community and the role of TSST-1-producing S. aureus in this disease in Libya.
\end{abstract}

\section{INTRODUCTION}

Staphylococcus aureus can potentially cause a wide range of infections, from relatively minor skin infections to lifethreatening systemic illnesses, in both healthy and immunocompromised people. However, the ability of $S$. aureus strains to produce disease, in both clinical and food settings, depends, among other determinants, on its ability to produce extracellular toxins. A number of staphylococcal enterotoxins (SEs), classified as A, B, C1, C2, C3, D or E, can be produced by some strains (Pimbley \& Patel, 1998). Most $S$. aureus strains isolated from patients with toxic shock syndrome (TSS), a severe acute illness that rapidly leads to multiorgan system failure, produce a toxin known as toxic shock syndrome toxin-1 (TSST-1). Although classically associated with tampon use, TSS has also been associated with a variety of non-menstruation-related conditions (Hertzer, 2001). Data regarding TSST-1 of S. aureus isolated in Libya are lacking. The present study was carried out to address such issues. In addition, isolates were tested for their susceptibility to antibiotics and were phage typed using the international phage set (IPS).

\section{METHODS}

Source and identification of $\boldsymbol{S}$. aureus strains. Sixty-three S. aureus strains from Libya were included in the present study; 40 were from clinical sources (wound, blood, ear, eye, throat and umbilical infections) and 23 were from food sources (meat, cake, ice cream and pizza). S. aureus strains were grown on blood agar at

Abbreviations: IPS, international phage set; MRSA, methicillin-resistant Staphylococcus aureus; SE, staphylococcal enterotoxins; TSS, toxic shock syndrome; TSST-1, toxic shock syndrome toxin-1. $37^{\circ} \mathrm{C}$. After overnight incubation, strains were examined by Gram stain and using catalase and coagulase tests as described previously (Duguid, 1989). Isolates were also tested using the Staphytect Plus kit (Oxoid) for identification of $S$. aureus.

Detection of the TSST-1 gene. The method described previously by Johnson \& Tyler (1993) was employed. One to two loopfuls of cells from test cultures on blood agar plates were used for DNA extraction after treatment with lysozyme (Sigma) and vortexing for 2 min. Relative molecular masses of the PCR products were obtained by size comparison with a $100 \mathrm{bp}$ ladder marker (Pharmacia). Detection of tst in S. aureus strains was carried out using PCR as described previously (Johnson \& Tyler, 1993). The sequences of the primers used were $5^{\prime}$-ATGGCAGCATCAGCTTGATA-3' and 5'TTTCCAATAACCACCCGTTT-3' (synthesized at the Agricultural Biotechnology Center, Gödöllö, Hungary). PCR conditions were as described previously (Johnson \& Tyler, 1993). Amplification was carried out in an Applied Biosystems GeneAmp PCR system using the following steps: 1 cycle at $94^{\circ} \mathrm{C}$ for 4 min followed by 30 cycles of denaturation for $2 \mathrm{~min}$ at $94^{\circ} \mathrm{C}$, annealing of primers for $2 \mathrm{~min}$ at $55^{\circ} \mathrm{C}$ and primer extension for $1 \mathrm{~min}$ at $72{ }^{\circ} \mathrm{C}$ with autoextension. After 30 cycles, the PCR tubes were incubated at $72^{\circ} \mathrm{C}$ for $7 \mathrm{~min}$ before cooling in the block to $4{ }^{\circ} \mathrm{C}$. Visualization of amplified products was carried out by electrophoresis through a $2 \%$ ultrapure agarose gel in $1 \times$ TBE buffer $(10 \times$ TBE is $108 \mathrm{~g}$ Tris, $55.5 \mathrm{~g}$ boric acid, $9 \cdot 3 \mathrm{~g}$ EDTA, $\mathrm{pH} 8 \cdot 3$, adjusted to $1000 \mathrm{ml}$ with water) and ethidium bromide staining. TSST-1-producing $S$. aureus was provided by Mr G. Kovacs (Department of Microbiology, Eötvös Loránd University, Budapest) and used as a positive control in all experiments.

S. aureus isolates that were positive for tst were tested further for the production of TSST-1 using the TST-RPLA kit (Oxoid) and for enterotoxin production using the SET-RPLA kit (Oxoid) according to the manufacturer's instructions.

Phage typing. The IPS was used, which consists of 23 bacteriophages for typing of human strains of $S$. aureus. The phages were 
group I: $29,52,52 \mathrm{~A}, 79,80$; group II: $3 \mathrm{~A}, 3 \mathrm{C}, 55,71$; group III: 6 , $42 \mathrm{E}, 47,53,54,75,77,83 \mathrm{~A}, 84,85 ; \mathrm{V}: 94,96$; and M (miscellaneous): 81,95 . A standard procedure for phage typing was employed (Blair \& Williams, 1961). All S. aureus strains included in the present study were phage typed with the exception of four clinical strains.

Antibiotic-susceptibility testing and $\boldsymbol{\beta}$-lactamase production. The susceptibility of the $S$. aureus strains to antimicrobial agents was measured in vitro using the disc-diffusion method (Bauer et al., 1966). Susceptibility to vancomycin was also tested by the agar dilution method (NCCLS, 2000). Production of $\beta$-lactamase by $S$. aureus strains was determined by an iodometric method (Sykes, 1978).

\section{RESULTS AND DISCUSSION}

The tst gene encoding TSST-1 was detected in only three $(7 \cdot 5 \%)$ of 40 Libyan S. aureus clinical strains and in none of the food strains. These three strains were also positive for TSST-1 using the TST-RPLA kit. Tsen et al. (1998) in Taiwan, also employing a PCR assay (using the TSST-1specific primers in the present study), reported closely similar findings. They identified only three $(4 \cdot 8 \%)$ of 62 strains of $S$. aureus from clinical sources as tst-carrying strains, but none of their food strains carried this gene.

Data concerning the status of TSS in Libya and the occurrence of TSST-1 in clinical and food strains of $S$. aureus from Libya and neighbouring countries are lacking. Since Staphylococcus infections are quite common in developing countries, it may be that this population has a higher antibody titre to TSST-1 than people in developed countries (Vergeront et al., 1983). This may be the reason that TSS has not been reported so far from Libya or from many developing countries.

Our findings and those of others (Tsen et al., 1998) indicate that production of TSST-1 from clinical sources other than TSS and from food is not a common phenomenon. This has been shown by several studies dealing with the detection of TSST-1 in S. aureus strains from TSS. Crass \& Bergdoll (1986) examined cultures of $S$. aureus from individuals with confirmed or probable TSS. They found that $91.6 \%$ of the isolates produced TSST-1 alone or in combination with one or more SEs.

It has been reported that co-production of SEC and TSST-1 or SEA and TSST-1 by S. aureus is common (Bohach et al., 1989; De Boer \& Chow, 1994; Johnson et al., 1991). The results obtained in the present study are in line with the findings of the above-mentioned studies. All three of the clinical S. aureus strains from Libya that were positive for TSST-1 were also producers of SEC, but not of SEA, using the SET-RPLA kit.

Phage typing using the IPS showed that $52.5 \%$ of S. aureus strains from Libya were untypeable. Al Bustan et al. (1996) found that $73 \%$ of $S$. aureus strains from nasal swabs of healthy restaurant workers in Kuwait City were untypeable with standard phages.
Marples \& Wieneke (1993) in the UK studied S. aureus strains from patients with diseases other than food poisoning. They observed strong associations between TSST-1 production and group I phage strains. In this study, TSST-1 was produced by only three clinical $S$. aureus strains (one belonged to phage group $\mathrm{V}$, one to a mixed phage group and one was untypeable); therefore, no conclusions could be drawn from our findings.

Antibiotic-resistance patterns of the S. aureus strains isolated from clinical and food sources in Libya are shown in Table 1 . Less than $50 \%$ of Libyan clinical strains were resistant to penicillin and were $\beta$-lactamase producers. However, almost $75 \%$ of Libyan strains originating from food were resistant to penicillin and were positive for $\beta$ lactamase. Fortunately, none of the Libyan S. aureus strains was resistant to methicillin or vancomycin.

Adesiyun et al. (1995) in Trinidad (a developing country) found that almost $75 \%$ of their S. aureus strains isolated from clinical and non-clinical human sources were resistant to penicillin, but only $0.7 \%$ were resistant to oxacillin, i.e. $0.7 \%$ were methicillin-resistant S. aureus (MRSA). High rates of MRSA reported by some workers could be due to misidentification of susceptible strains of $S$. aureus as MRSA (Hoebe et al., 1999). Although it appears from the results obtained in the present work that resistance to methicillin might not be a problem amongst $S$. aureus strains in Tripoli,

Table 1. Antibiotic-resistance patterns of $S$. aureus strains isolated from clinical and food sources in Tripoli, Libya

Values are numbers (percentages) of resistant strains.

\begin{tabular}{|lcc|}
\hline Antibiotic & $\begin{array}{c}\text { Clinical strains } \\
(\boldsymbol{n}=\mathbf{4 0})\end{array}$ & $\begin{array}{c}\text { Food strains } \\
(\boldsymbol{n}=\mathbf{2 3})\end{array}$ \\
\hline Penicillin & $18(45)$ & $17(73 \cdot 9)$ \\
Ampicillin & $18(45)$ & $17(73 \cdot 9)$ \\
Ampicillin/clavulanic acid & $0(0 \cdot 0)$ & $0(0 \cdot 0)$ \\
Azlocillin & $18(45)$ & $17(73 \cdot 9)$ \\
Carbenicillin & $18(45)$ & $17(73 \cdot 9)$ \\
Methicillin & $0(0 \cdot 0)$ & $0(0 \cdot 0)$ \\
Cefamandol & $0(0 \cdot 0)$ & $0(0 \cdot 0)$ \\
Cefalexin & $0(0 \cdot 0)$ & $0(0 \cdot 0)$ \\
Ceftriaxone & $0(0 \cdot 0)$ & $0(0 \cdot 0)$ \\
Ceftazidime & $0(0 \cdot 0)$ & $0(0 \cdot 0)$ \\
Amikacin & $0(0 \cdot 0)$ & $0(0 \cdot 0)$ \\
Tobramycin & $0(0 \cdot 0)$ & $0(0 \cdot 0)$ \\
Gentamicin & $0(0 \cdot 0)$ & $0(0 \cdot 0)$ \\
Clindamycin & $0(0 \cdot 0)$ & $0(0 \cdot 0)$ \\
Ciprofloxacin & $0(0 \cdot 0)$ & $1(4 \cdot 3)$ \\
Ofloxacin & $0(0 \cdot 0)$ & $1(4 \cdot 3)$ \\
Pefloxacin & $0(0 \cdot 0)$ & $1(4 \cdot 3)$ \\
Erythromycin & $0(0 \cdot 0)$ & $2(8 \cdot 7)$ \\
Tetracycline & $7(17 \cdot 5)$ & $6(26 \cdot 1)$ \\
Vancomycin & $0(0 \cdot 0)$ & $0(0 \cdot 0)$ \\
& & \\
\hline
\end{tabular}


Table 2. Phage types of antibiotic-resistant $S$. aureus strains from Tripoli, Libya

Values are numbers (percentages). Phage group M, miscellaneous.

\begin{tabular}{|lllllllrr|}
\hline \multirow{2}{*}{ Source } & \multicolumn{9}{c}{} & \multicolumn{4}{c}{ Strains lysed by phage group: } & \multicolumn{2}{c}{ Total } \\
\cline { 2 - 7 } & \multicolumn{1}{c}{ I } & II & III & V & M & Mixed & Untypeable \\
\hline Clinical & $1(5 \cdot 25)$ & $3(15 \cdot 8)$ & $1(5 \cdot 3)$ & $3(15 \cdot 8)$ & $1(5 \cdot 25)$ & $2(10 \cdot 5)$ & $8(42 \cdot 1)$ \\
Food & $0(0 \cdot 0)$ & $4(23 \cdot 5)$ & $2(11 \cdot 8)$ & $0(0 \cdot 0)$ & $1(5 \cdot 9)$ & $0(0 \cdot 0)$ & $10(58 \cdot 8)$ & $19(52 \cdot 8)$ \\
Total & $1(2 \cdot 7)$ & $7(19 \cdot 4)$ & $3(8 \cdot 3)$ & $3(8 \cdot 3)$ & $2(5 \cdot 6)$ & $2(5 \cdot 6)$ & $18(50 \cdot 0)$ & 36 \\
\end{tabular}

Libya, more studies are needed in this field to confirm this finding.

Several studies (Kimura et al., 1992; Shimaoka et al., 1996) have shown that the TSST-1 gene is more prevalent in MRSA than in methicillin-susceptible $S$. aureus. This may explain why tst was detected in only a small number of the strains examined in the present study.

The phage types of the antibiotic-resistant $S$. aureus strains from Tripoli are shown in Table 2. A number of investigators have found that strains of $S$. aureus lysed by group II phages are highly resistant to antimicrobial agents (Rosdahl et al., 1990; Ross et al., 1974). Most of the Libyan S. aureus strains that were resistant to antibiotics were either lysed by group II phages or were untypeable. However, the percentage of resistant strains lysed by group II phages was relatively small compared with that reported by Adesiyun et al. (1995). These researchers found that nearly $86 \%$ of their $S$. aureus strains lysed by group II phages were resistant to antimicrobial agents compared with approximately 16 and $24 \%$ of Libyan clinical and food strains, respectively. These differences could be due to the fact that $<50 \%$ of the Libyan strains were typeable by the IPS compared with $>80 \%$ of strains in the study by Adesiyun et al. (1995).

This is the first time that PCR detection of the TSST-1 gene in $S$. aureus has been reported from Libya, and further studies are needed on the occurrence of TSS in the community and the role of TSST-1-producing S. aureus in this disease in Libya.

\section{REFERENCES}

Adesiyun, A. A., Prabhakar, P., Ali, C. \& Lewis, M. (1995). Characteristics of Staphylococcus aureus strains isolated from clinical and nonclinical human sources in Trinidad: susceptibility to bacteriophages and antimicrobial agents, and toxigenicity. Zentralbl Bakteriol 282, 519-532.

al Bustan, M. A., Udo, E. E. \& Chugh, T. D. (1996). Nasal carriage of enterotoxin-producing Staphylococcus aureus among restaurant workers in Kuwait City. Epidemiol Infect 116, 319-322.

Bauer, A. W., Kirby, W. M. M., Sherris, J. C. \& Turck, M. (1966). Antibiotic susceptibility testing by a standardized single disk method. Am J Clin Pathol 45, 493-496.

Blair, J. E. \& Williams, R. E. O. (1961). Phage typing of Staphylococci. Bull World Health Organ 24, 771-784.
Bohach, G. A., Kreiswirth, B. N., Novick, R. P. \& Schlievert, P. M. (1989). Analysis of toxic shock syndrome isolates producing staphylococcal enterotoxin B and C1 with use of Southern hybridization and immunologic assays. Rev Infect Dis 11, S75-S81.

Crass, B. A. \& Bergdoll, M. S. (1986). Toxin involvement in toxic shock syndrome. J Infect Dis 153, 918-926.

De Boer, M. L. \& Chow, A. W. (1994). Toxic shock syndrome toxin 1producing Staphylococcus aureus isolates contain the staphylococcal enterotoxin B genetic element but do not express staphylococcal enterotoxin B. J Infect Dis 170, 818-827.

Duguid, J. P. (1989). Staphylococcus: cluster-forming Gram-positive cocci. In Practical Medical Microbiology, 13th edn, pp. 303-316. Edited by J. G. Collee, J. P. Duguid, A. G. Fraser \& B. P. Marmion. Edinburgh: Churchill Livingstone.

Hertzer, C. M. (2001). Toxic shock syndrome: broadening the differential diagnosis. J Am Board Fam Pract 14, 131-136.

Hoebe, C. J. P., Wagenvoort, J. H. T., Bilkert-Mooiman, M. A. J. \& van Leewen, W. J. (1999). An alleged outbreak of methicillinresistant Staphylococcus aureus in a Dutch nursing home. Eur J Clin Microbiol Infect Dis 18, 751-752.

Johnson, W. M. \& Tyler, S. D. (1993). PCR detection of genes for enterotoxins, exfoliative toxins, and toxic shock syndrome toxin-1 in Staphylococcus aureus. In Diagnostic Molecular Microbiology: Principles and Applications, pp. 294-299. Edited by D. H. Persing, T. F. Smith, F. C. Tenover \& T. J. White. Washington, DC: American Society for Microbiology.

Johnson, W. M., Tyler, S. D., Ewan, E. P., Ashton, F. E., Pollard, D. R. \& Rozee, K. R. (1991). Detection of genes for enterotoxins, exfoliative toxins, and toxic shock syndrome toxin 1 in Staphylococcus aureus by polymerase chain reaction. J Clin Microbiol 29, 426-430.

Kimura, A., Igarashi, H., Ushioda, H., Okuzumi, K., Kobayashi, H. \& Otsuka, T. (1992). Epidemiological study of Staphylococcus aureus isolated from the Japanese National University and Medical College Hospitals with coagulase typing, and production of enterotoxins and toxic shock syndrome toxin-1. Kansenshogaku Zasshi 66, 1543-1549 (in Japanese).

Marples, R. R. \& Wieneke, A. A. (1993). Enterotoxins and toxic-shock syndrome toxin-1 in non-enteric staphylococcal disease. Epidemiol Infect 110, 477-488.

NCCLS (2000). Methods for dilution antimicrobial susceptibility tests for bacteria that grow aerobically. Approved standard, 5th edn. NCCLS document M7-A5. Wayne, PA: National Committee for Clinical Laboratory Standards.

Pimbley, D. W. \& Patel, P. D. (1998). A review of analytical methods for the detection of bacterial toxins. J Appl Microbiol 84 (Suppl. 1), 98S-109S.

Rosdahl, V. T., Westh, H. \& Jensen, K. (1990). Antibiotic susceptibility and phage-type pattern of Staphylococcus aureus strains isolated 
from patients in general practice compared to strains from hospitalized patients. Scand J Infect Dis 22, 315-320.

Ross, S., Rodriguez, W., Controni, G. \& Khan, W. (1974). Staphylococcal susceptibility to penicillin $\mathrm{G}$. The changing patterns among community strains. JAMA 229, 1075-1077.

Shimaoka, M., Yoh, M., Takarada, Y., Yamamoto, K. \& Honda, T. (1996). Detection of the gene for toxic shock syndrome toxin 1 in Staphylococcus aureus by enzyme-labelled oligonucleotide probes. $J$ Med Microbiol 44, 215-218.

Sykes, R. B. (1978). Methods for detecting beta-lactamases. In Laboratory Methods in Antimicrobial Chemotherapy, pp. 64-69.
Edited by D. S. Reeves, I. Phillips, J. D. Williams \& R. Wise. Edinburgh: Churchill Livingstone.

Tsen, H. Y., Yu, G. K., Wang, K. C., Wang, S. J., Chang, M. Y. \& Lin, L. Y. (1998). Comparison of enterotoxigenic types, toxic shock syndrome toxin 1 (TSST-1) strains and antibiotic susceptibilities for enterotoxigenic Staphylococcus aureus strains isolated from food and clinical samples. Food Microbiol 15, 33-41.

Vergeront, J. M., Stoltz, S. J., Crass, B. A., Nelson, D. B., Davies, J. P. \& Bergdoll, M. S. (1983). Prevalence of serum antibody to staphylococcal enterotoxin $\mathrm{F}$ among Wisconsin residents: implications for toxic-shock syndrome. J Infect Dis 148, 692-698. 